\title{
Sufficient Conditions for Non-Bazilevič Functions
}

\author{
Qun-Fa Cui, ${ }^{1}$ Zhi-Gang Wang, ${ }^{1}$ Xiao-Hong Chen, ${ }^{2}$ and Feng-Hua Wen ${ }^{2}$ \\ ${ }^{1}$ School of Mathematics and Statistics, Anyang Normal University, Anyang, Henan 455002, China \\ ${ }^{2}$ School of Business, Central South University, Changsha, Hunan 410083, China \\ Correspondence should be addressed to Feng-Hua Wen; wfh@amss.ac.cn \\ Received 11 July 2013; Accepted 19 September 2013 \\ Academic Editor: Alberto Fiorenza \\ Copyright (C) 2013 Qun-Fa Cui et al. This is an open access article distributed under the Creative Commons Attribution License, \\ which permits unrestricted use, distribution, and reproduction in any medium, provided the original work is properly cited. \\ The main purpose of this paper is to derive some sufficient conditions for analytic functions to be of non-Bazilevič type.
}

\section{Introduction}

Let $\mathscr{A}$ denote the class of functions of the form

$$
f(z)=z+\sum_{j=2}^{\infty} a_{j} z^{j}
$$

which are analytic in the open unit disk:

$$
\mathbb{U}:=\{z: z \in \mathbb{C},|z|<1\} .
$$

For $0 \leqq \alpha<1$ and $0<\mu<1$, a function $f \in \mathscr{A}$ is said to be in the class $\mathcal{N}(\mu, \alpha)$ if it satisfies the condition

$$
\Re\left(f^{\prime}(z)\left(\frac{z}{f(z)}\right)^{1+\mu}\right)>\alpha, \quad(z \in \mathbb{U}) .
$$

As usual, the class $\mathcal{N}(\mu, \alpha)$ is said to be non-Bazilevič functions of order $\alpha$ (see [1]).

For some recent investigations of non-Bazilevič functions, see, for example the works of [2-6] and the references cited therein.

For two functions $f$ and $g$, analytic in $\mathbb{U}$, we say that the function $f$ is subordinate to $g$ in $\mathbb{U}$ and write

$$
f(z) \prec g(z), \quad(z \in \mathbb{U}),
$$

if there exists a Schwarz function $\omega$, which is analytic in $\mathbb{U}$ with

$$
\omega(0)=0, \quad|\omega(z)|<1, \quad(z \in \mathbb{U}),
$$

such that

$$
f(z)=g(\omega(z)), \quad(z \in \mathbb{U}) .
$$

Indeed, it is known that

$$
\begin{gathered}
f(z) \prec g(z), \\
(z \in \mathbb{U}) \Longrightarrow f(0)=g(0), \quad f(\mathbb{U}) \subset g(\mathbb{U}) .
\end{gathered}
$$

Furthermore, if the function $g$ is univalent in $\mathbb{U}$, then we have the following equivalence:

$$
\begin{gathered}
f(z) \prec g(z), \\
(z \in \mathbb{U}) \Longrightarrow f(0)=g(0), \quad f(\mathbb{U}) \subset g(\mathbb{U}) .
\end{gathered}
$$

To derive our main results, we need the following lemmas.

Lemma 1 (see [7]). Let $\mathfrak{p}(z)=1+b_{1} z+b_{2} z^{2}+\cdots$ be analytic in $\mathbb{U}$ and let $\mathfrak{h}$ be analytic and starlike (with respect to the origin) univalent in $\mathbb{U}$ with $\mathfrak{h}(0)=0$. If

$$
z \mathfrak{p}^{\prime}(z) \prec \mathfrak{h}(z),
$$

then

$$
\mathfrak{p}(z) \prec 1+\int_{0}^{z} \frac{\mathfrak{h}(t)}{t} d t
$$

Lemma 2 (see [8]). Let $q$ be univalent in $\mathbb{U}$. Also let $\phi$ be analytic in the domain $\mathbb{D}$ containing $q(\mathbb{U})$ with $\phi(\omega) \neq 0$ when $\omega \in q(\mathbb{U})$. Set

$$
Q(z)=z q^{\prime}(z) \phi(q(z)), \quad h(z)=\theta(q(z))+Q(z) .
$$


Suppose that

(1) $Q(z)$ is starlike univalent in $\mathbb{U}$;

(2) $\mathfrak{R}\left(z h^{\prime}(z) / Q(z)\right)=\mathfrak{R}\left(\left(\theta^{\prime}(q(z)) / \phi(q(z))\right)+\left(z Q^{\prime}(z) /\right.\right.$ $Q(z)))>0$ for $z \in \mathbb{U}$.

If $p$ is analytic in $\mathbb{U}$ with $p(0)=q(0), p(\mathbb{U}) \subset \mathbb{D}$ and

$$
\theta(p(z))+z p^{\prime}(z) \phi(p(z)) \prec \theta(q(z))+z q^{\prime}(z) \phi(q(z)),
$$

then $p \prec q$, and $q$ is the best dominant.

Lemma 3 (see [9]). Let $\Omega$ be a set in the complex plane $\mathbb{C}$ and suppose that $\Phi$ is a mapping from $\mathbb{C}^{2} \times \mathbb{U}$ to $\mathbb{C}$ which satisfies $\Phi(i x, y ; z) \notin \Omega$ for $z \in \mathbb{U}$ and for all real $x, y$ such that $y \leqq$ $-\left(1+x^{2}\right) / 2$.

If the function $p(z)=1+c_{1} z+c_{2} z^{2}+\cdots$ is analytic in $\mathbb{U}$ and $\Phi\left(p(z), z p^{\prime}(z) ; z\right) \in \Omega$ for all $z \in \mathbb{U}$, then $\mathfrak{R}(p(z))>0$.

In this paper, we aim at proving some sufficient conditions for analytic functions to be of non-Bazilevič type.

\section{Main Results}

Our first main result is given by Theorem 4 .

Theorem 4. Suppose that $h(z)$ is starlike in $\mathbb{U}$ with $h(0)=0$. If

$$
\frac{z f^{\prime \prime}(z)}{f^{\prime}(z)}+(1+\mu)\left(1-\frac{z f^{\prime}(z)}{f(z)}\right) \prec h(z), \quad(0<\mu<1),
$$

then

$$
f^{\prime}(z)\left(\frac{z}{f(z)}\right)^{1+\mu} \prec \exp \left(1+\int_{0}^{z} \frac{h(t)}{t} d t\right) .
$$

Proof. We define the function $p$ by

$$
p(z):=f^{\prime}(z)\left(\frac{z}{f(z)}\right)^{1+\mu}, \quad(z \in \mathbb{U} ; 0<\mu<1) .
$$

Then $p$ is analytic in $\mathbb{U}$ with $p(0)=1$. It follows from (15) that

$$
\begin{array}{r}
z(\log (p(z)))^{\prime}=\frac{z f^{\prime \prime}(z)}{f^{\prime}(z)}+(1+\mu)\left(1-\frac{z f^{\prime}(z)}{f(z)}\right) \\
(0<\mu<1) .
\end{array}
$$

Combining (13) and (16), we find that

$$
z(\log (p(z)))^{\prime} \prec h(z)
$$

By Lemma 1, we deduce that

$$
\log (p(z)) \prec 1+\int_{0}^{z} \frac{h(t)}{t} d t .
$$

From (15) and (18), we readily get the assertion (14) of Theorem 4.
Theorem 5. If $f \in \mathscr{A}$ satisfies the inequality

$$
\begin{aligned}
& \mid\left[\frac{z f^{\prime \prime}(z)}{f^{\prime}(z)}+(1+\mu)\left(1-\frac{z f^{\prime}(z)}{f(z)}\right)\right] \\
& \times\left(f^{\prime}(z)\left(\frac{z}{f(z)}\right)^{1+\mu}\right)^{-1} \mid<v, \quad(0<\mu, \quad v<1),
\end{aligned}
$$

then $f \in \mathscr{N}(\mu, 1 /(1+\nu))$.

Proof. Suppose that the function $p$ is defined by (15). It follows that

$$
\begin{aligned}
z\left(\frac{1}{p(z)}\right)^{\prime}= & -\left[\frac{z f^{\prime \prime}(z)}{f^{\prime}(z)}+(1+\mu)\left(1-\frac{z f^{\prime}(z)}{f(z)}\right)\right] \\
& \times\left(f^{\prime}(z)\left(\frac{z}{f(z)}\right)^{1+\mu}\right)^{-1} .
\end{aligned}
$$

Combining (19) and (20), we know that

$$
z\left(\frac{1}{p(z)}\right)^{\prime} \prec v z
$$

An application of Lemma 1 to (21) yields

$$
p(z) \prec \frac{1}{1+v z}=: q(z) .
$$

By noting that

$$
\Re\left(1+\frac{z q^{\prime \prime}(z)}{q^{\prime}(z)}\right)=\mathfrak{R}\left(\frac{1-v z}{1+v z}\right) \geqq \frac{1-v}{1+v}>0,
$$

$(0<v<1 ; z \in \mathbb{U})$

which implies that the region $q(\mathbb{U})$ is symmetric with respect to the real axis and $q$ is convex univalent in $\mathbb{U}$ therefore, we have

$$
\mathfrak{R}(q(z)) \geqq q(1) \geqq 0, \quad(z \in \mathbb{U}) .
$$

Combining (15), (22), and (24), we conclude that

$$
\Re\left(f^{\prime}(z)\left(\frac{z}{f(z)}\right)^{1+\mu}\right)>\frac{1}{1+v}, \quad(0<v<1 ; z \in \mathbb{U}) .
$$

This completes the proof of Theorem 5 .

Theorem 6. Suppose that $q$ is convex in $\mathbb{U}$ with $q(0)=1$. If

$$
\begin{gathered}
\mathfrak{R}(\lambda q(z))>0, \quad(z \in \mathbb{U} ; \lambda \in \mathbb{C}), \\
{\left[\frac{z f^{\prime \prime}(z)}{f^{\prime}(z)}+(1+\mu)\left(1-\frac{z f^{\prime}(z)}{f(z)}\right)\right] f^{\prime}(z)\left(\frac{z}{f(z)}\right)^{1+\mu}} \\
+\lambda\left(f^{\prime}(z)\left(\frac{z}{f(z)}\right)^{1+\mu}\right)^{2} \prec z q^{\prime}(z)+\lambda q^{2}(z)
\end{gathered}
$$


then

$$
f^{\prime}(z)\left(\frac{z}{f(z)}\right)^{1+\mu} \prec q(z),
$$

and $q$ is the best dominant.

Proof. Suppose that the function $p$ is defined by (15). It follows that

$$
\begin{aligned}
z p^{\prime}(z)+\lambda p^{2}(z)= & {\left[\frac{z f^{\prime \prime}(z)}{f^{\prime}(z)}+(1+\mu)\left(1-\frac{z f^{\prime}(z)}{f(z)}\right)\right] } \\
& \times f^{\prime}(z)\left(\frac{z}{f(z)}\right)^{1+\mu} \\
& +\lambda\left(f^{\prime}(z)\left(\frac{z}{f(z)}\right)^{1+\mu}\right)^{2} .
\end{aligned}
$$

We now assume that

$$
\theta(\omega)=\lambda \omega^{2}, \quad \phi(\omega)=1 .
$$

Obviously, $\theta(\omega)$ and $\phi(\omega)$ are analytic in the $\omega$ plane. By noting that the function

$$
Q(z)=z p^{\prime}(z) \phi(p(z))=z p^{\prime}(z)
$$

is starlike in $\mathbb{U}$ and

$$
\chi(z)=\theta(p(z))+Q(z)=\lambda p^{2}(z)+z p^{\prime}(z),
$$

it follows from (26) that

$$
\Re\left(\frac{z \chi^{\prime}(z)}{Q(z)}\right)=\Re\left(2 \lambda p(z)+\frac{z Q^{\prime}(z)}{Q(z)}\right)>0 .
$$

Combining (27), (29), and Lemma 2, we get the assertion of Theorem 6 .

Remark 7. By taking suitable $h(z)$ and $q(z)$ in Theorems 4 and 6 , respectively, we can get some useful consequences. Here we choose to omit the details.

Theorem 8. If $f \in \mathscr{A}$ satisfies the condition

$$
\begin{aligned}
& \frac{f^{1+\mu}(z)}{z^{\mu} f^{\prime}(z)}\left(f^{\prime}(z)\left(\frac{z}{f(z)}\right)^{1+\mu}\right)^{\prime} \\
& > \begin{cases}\frac{\gamma}{2(\gamma-1)}, & \left(0 \leqq \gamma \leqq \frac{1}{2}\right), \\
\frac{\gamma-1}{2 \gamma}, & \left(\frac{1}{2} \leqq \gamma<1\right),\end{cases}
\end{aligned}
$$

then $f \in \mathcal{N}(\mu, \gamma)$.

Proof. Suppose that

$$
\psi(z):=\frac{f^{\prime}(z)(z / f(z))^{1+\mu}-\gamma}{1-\gamma}, \quad(0 \leqq \gamma<1 ; z \in \mathbb{U}) .
$$

Then $\psi$ is analytic in $\mathbb{U}$. It follows from (35) that

$$
\begin{aligned}
\frac{f^{1+\mu}(z)}{z^{\mu} f^{\prime}(z)}\left(f^{\prime}(z)\left(\frac{z}{f(z)}\right)^{1+\mu}\right)^{\prime} & =\frac{(1-\gamma) z \psi^{\prime}(z)}{\gamma+(1-\gamma) \psi(z)} \\
& =\Phi\left(\psi(z), z \psi^{\prime}(z) ; z\right),
\end{aligned}
$$

where

$$
\Phi(r, s ; t)=\frac{(1-\gamma) s}{\gamma+(1-\gamma) r}
$$

For all real $x$ and $y$ satisfying $y \leqq-\left(1+x^{2}\right) / 2$, we have

$$
\begin{aligned}
\mathfrak{R}(\Phi(i x, y ; z)) & =\frac{(1-\gamma) \gamma y}{\gamma^{2}+(1-\gamma)^{2} x^{2}} \\
& \leqq-\frac{(1-\gamma) \gamma}{2} \cdot \frac{1+x^{2}}{\gamma^{2}+(1-\gamma)^{2} x^{2}} \\
& \leqq\left\{\begin{array}{l}
-\frac{(1-\gamma) \gamma}{2} \cdot \frac{1}{(1-\gamma)^{2}}, \quad\left(0 \leqq \gamma \leqq \frac{1}{2}\right), \\
-\frac{(1-\gamma) \gamma}{2} \cdot \frac{1}{\gamma^{2}}, \quad\left(\frac{1}{2} \leqq \gamma<1\right) .
\end{array}\right.
\end{aligned}
$$

We now put

$$
\Omega=\left\{\xi: \Re(\xi)>\left\{\begin{array}{ll}
\frac{\gamma}{2(\gamma-1)} & \left(0 \leqq \gamma \leqq \frac{1}{2}\right) \\
\frac{\gamma-1}{2 \gamma} & \left(\frac{1}{2} \leqq \gamma<1\right)
\end{array}\right\} .\right.
$$

Then $\Phi(i x, y ; z) \notin \Omega$ for all real $x, y$ such that $y \leqq-\left(1+x^{2}\right) / 2$. Moreover, in view of (34), we know that $\Phi\left(\psi(z), z \psi^{\prime}(z) ; z\right) \epsilon$ $\Omega$. Thus, by Lemma 3, we deduce that

$$
\mathfrak{R}(\psi(z))>0, \quad(z \in \mathbb{U}),
$$

which shows that the desired assertion of Theorem 8 holds.

\section{Acknowledgments}

The present investigation was supported by the National Natural Science Foundation under Grant nos. 11301008, 11226088, 71171024, 71371195, and 70921001 and the Key Project of Natural Science Foundation of Educational Committee of Henan Province under Grant no. 12A110002 of the People's Republic of China.

\section{References}

[1] M. Obradović, "A class of univalent functions," Hokkaido Mathematical Journal, vol. 27, no. 2, pp. 329-335, 1998. 
[2] M. Obradović, S. Ponnusamy, and P. Vasundhra, "Univalence and starlikeness of nonlinear integral transform of certain class of analytic functions," Indian Academy of Sciences. Proceedings Mathematical Sciences, vol. 119, no. 5, pp. 593-610, 2009.

[3] T. N. Shanmugam, S. Sivasubramanian, M. Darus, and S. Kavitha, "On sandwich theorems for certain subclasses of nonBazilevič functions involving Cho-Kim transformation," Complex Variables and Elliptic Equations, vol. 52, no. 10-11, pp. 10171028, 2007.

[4] T. N. Shanmugam, S. Sivasubramanian, B. A. Frasin, and S. Kavitha, "On sandwich theorems for certain subclasses of analytic functions involving Carlson-Shaffer operator," Journal of the Korean Mathematical Society, vol. 45, no. 3, pp. 611-620, 2008.

[5] N. Tuneski and M. Darus, "Fekete-Szegö functional for nonBazilevič functions," Acta Mathematica Academiae Paedagogicae Nyíregyháziensis (New Series), vol. 18, no. 2, pp. 63-65, 2002.

[6] Z. Wang, C. Gao, and M. Liao, "On certain generalized class of non-Bazilevič functions," Acta Mathematica Academiae Paedagogicae Nyíregyháziensis (New Series), vol. 21, no. 2, pp. 147-154, 2005.

[7] D. Yang, "Some criteria for multivalently starlikeness," Southeast Asian Bulletin of Mathematics, vol. 24, no. 3, pp. 491-497, 2000.

[8] S. S. Miller and P. T. Mocanu, Differential Subordinations, Theory and Applications, vol. 225, Marcel Dekker, New York, NY, USA, 2000.

[9] S. S. Miller and P. T. Mocanu, "Differential subordinations and inequalities in the complex plane," Journal of Differential Equations, vol. 67, no. 2, pp. 199-211, 1987. 


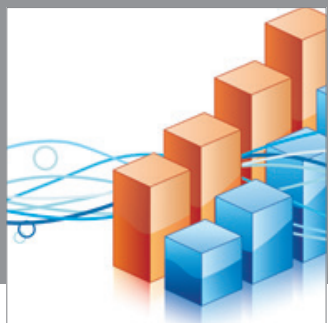

Advances in

Operations Research

mansans

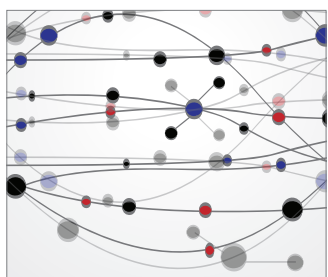

The Scientific World Journal
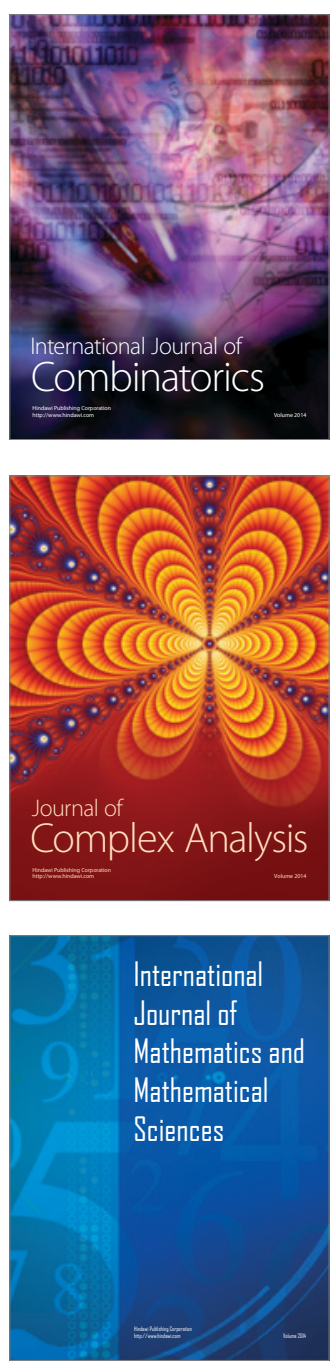
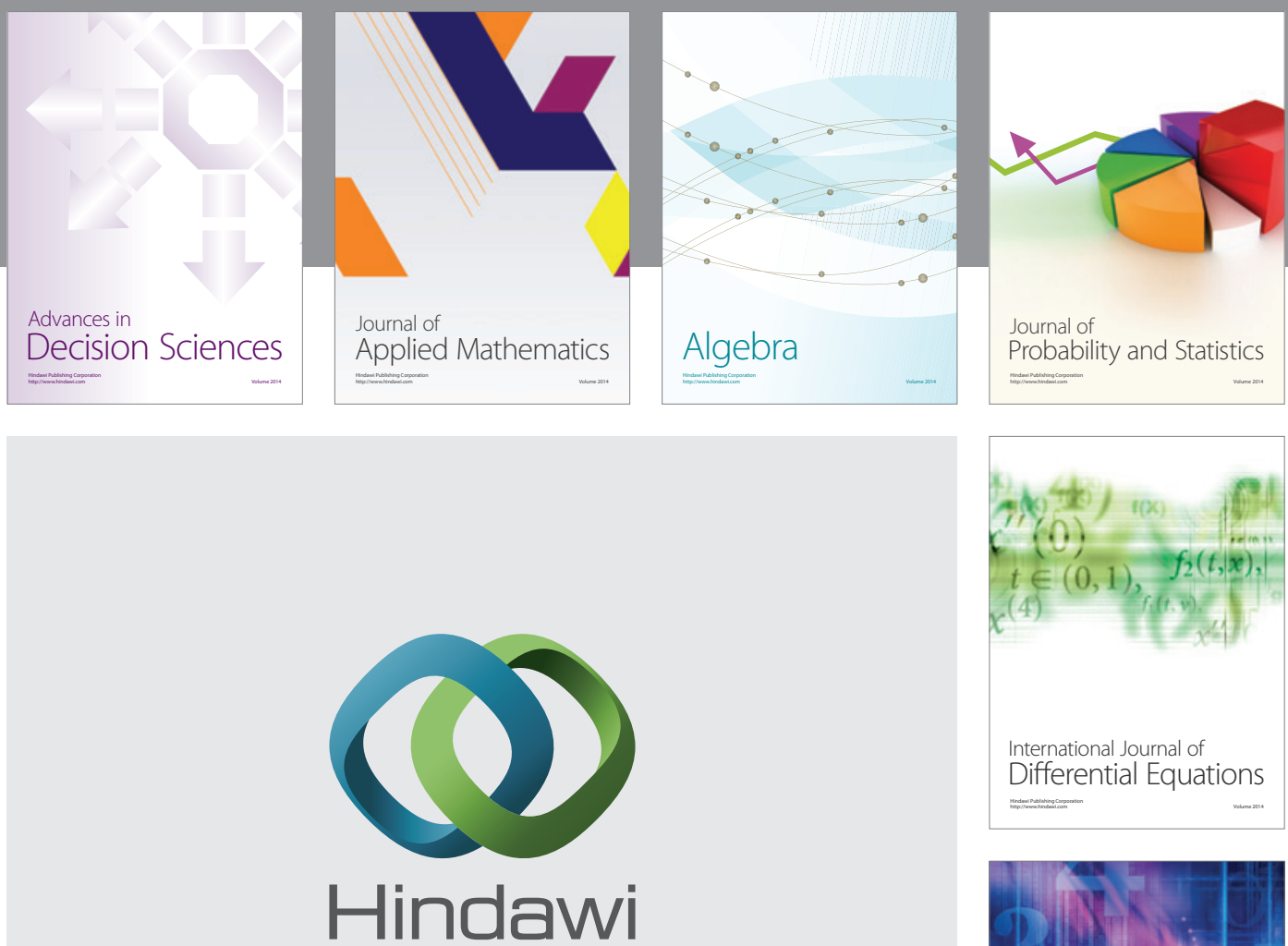

Submit your manuscripts at http://www.hindawi.com
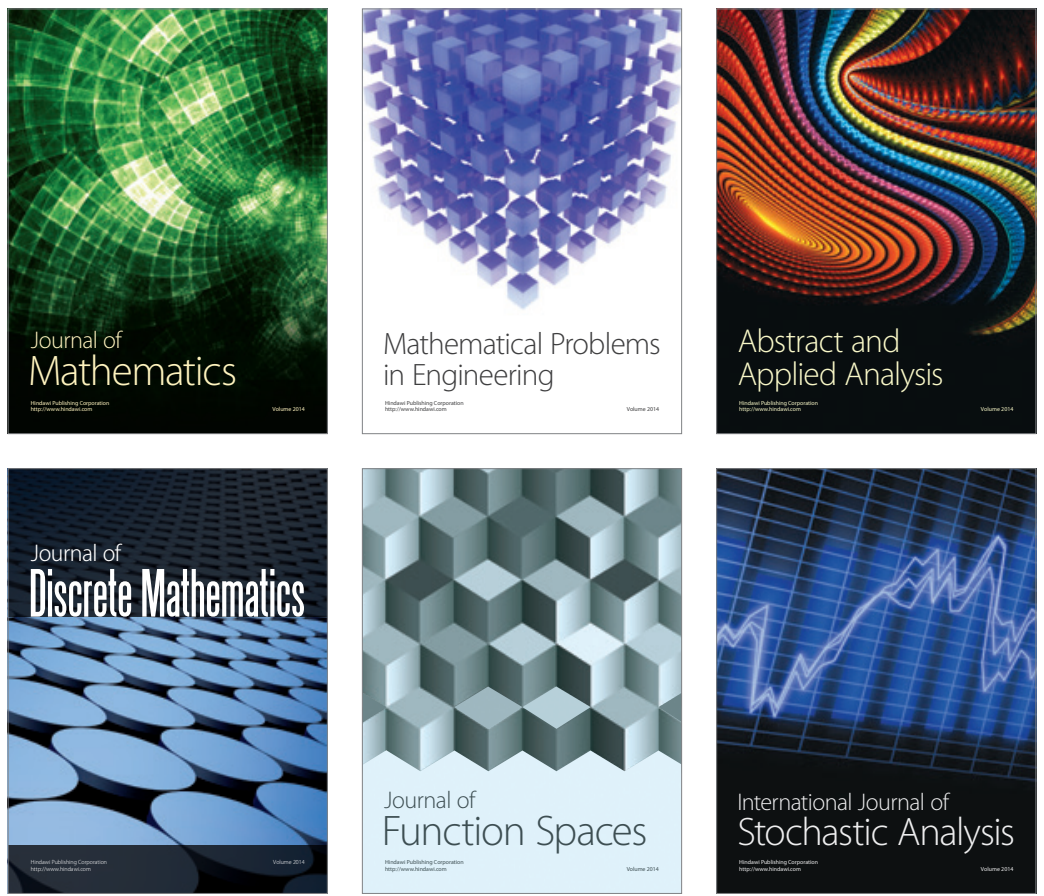

Journal of

Function Spaces

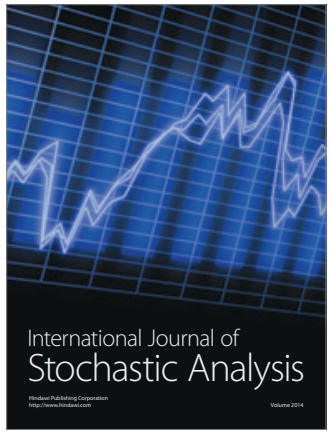

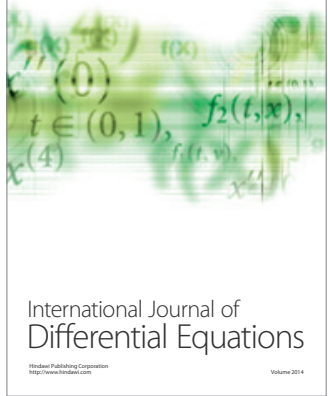
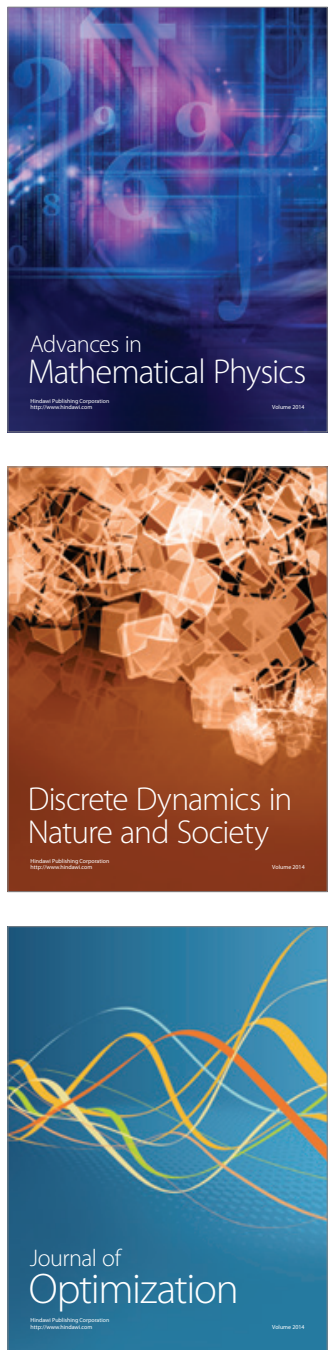